International Journal of Pure and Applied Mathematics

Volume 114 No. 3 2017, 553-570

ISSN: 1311-8080 (printed version); ISSN: 1314-3395 (on-line version)

url: http://www.ijpam.eu

doi: 10.12732/ijpam.v114i3.11

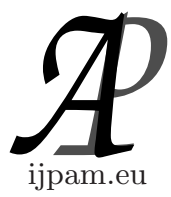

\title{
ON VERTEX PRODUCT CORDIAL LABELING
}

\author{
Neelam Kumari ${ }^{1}$, Seema Mehra ${ }^{2}$ \\ ${ }^{1,2}$ Department of Mathematics \\ M.D. University \\ Rohtak, 124001, Haryana, INDIA
}

\begin{abstract}
In this paper, we define the vertex product cordial labeling for some path related graphs like $P_{n}^{2}$, path union of $k$ copies of $P_{n}^{2}$ graph and $P_{n} \odot K_{1}$. We also discuss vertex product cordial labeling of helm graph and some graphs related to gear graph. In the present paper, we also show that the graph obtained from cycle $C_{n}$ after switching of a vertex admits vertex product cordial labeling. Moreover we show that corona product $C_{n} \odot K_{1}$, ladder graph $P_{n} \times P_{2}$ with one edge path to one vertex, $C_{n} \odot \bar{K}_{m}$ and the banana tree $B T\left(n_{1}, n_{2}, n_{3}\right)$ also admits vertex product cordial labeling with certain conditions.
\end{abstract}

AMS Subject Classification: $05 \mathrm{C} 78$

Key Words: vertex product cordial graph, gear graphs, Banana tree, Ladder graph, corona product

\section{Introduction}

All graphs considered are finite, connected, undirected and simple. The graphs has the vertex set $V(G)$ and edge set $E(G)$ where $|V(G)|=p$ and $|E(G)|=q$. Graph labeling is an assignment of integers to vertices or edges or both vertices and edges of the graph subject to certain conditions. If the domain of the mapping is the set of vertices (or edges) then the labeling is called a vertex labeling (or an edge labeling). All terms and definitions, not defined specifically in this paper, we refer to Rosa and Harary [4,5].

Received: December 30, 2016

Revised: $\quad$ April 8, 2017

Published: $\quad$ May 23, 2017

(c) 2017 Academic Publications, Ltd. url: www.acadpubl.eu

$\S_{\text {Correspondence author }}$ 
The origin of graph labeling is graceful labeling which was introduced by Rosa [5] in 1967. The concept of cordial labeling was introduced by Cahit [1] in 1987 as a weaker version of graceful and harmonious labeling. He write down a paper in which he investigated several results on this newly defined concept. Some labeling with variations in cordial labeling have been introduced such as prime cordial labeling, E-cordial labeling, product cordial labeling and total product cordial labeling. Cordiality behavior of numerous graph were studied by several authors $[10,11,12,13]$. The notion of product cordial labeling was introduced by Sundaram [10] in which the absolute difference in cordial labeling is replaced by product of the vertex labels.

The present work is focused on vertex product cordial labeling of graphs. S.M. Lee and A. Liu [2] proved that all complete bipartite and all fans are cordial. Further, they proved that, the cycle $C_{n}$ is cordial if and only if $n \not \equiv$ $2(\bmod 4)$, the wheel $W_{n}$ is cordial if and only if $n \neq \equiv(\bmod 4), n \geq 3$. In this section we provide brief summary of definitions and other required information for our investigation.

Definition 1.1. A labeling $f: V(G) \rightarrow\{0,1\}$ is called binary vertex labeling of $G$ and $f(v)$ is called the label of the vertex $v$ of $G$ under $f$.

Notation. If for any edge $e=u v$, the induced edge labeling $f^{*}: E(G) \rightarrow\{0,1\}$ is given by $f^{*}(e)=|f(u)-f(v)|$. Then

$$
\begin{aligned}
& v_{f}(i)=\text { number of vertices of } G \text { having label } i \text { under } f, \\
& e_{f^{*}}(i)=\text { number of vertices of } G \text { having label } i \text { under } f^{*},
\end{aligned}
$$

where $i=0,1$.

Definition 1.2. A binary vertex labeling $f$ of a graph $G$ is called a cordial labeling if $\left|v_{f}(1)-v_{f}(0)\right| \leq 1$ and $\left|e_{f^{*}}(1)-e_{f^{*}}(0)\right| \leq 1$. A graph $G$ is cordial if it admits cordial labeling.

In 2004, the notion of product cordial labeling was originated by Sundaram, Ponraj and Somasundaram et al. [10].

Definition 1.3. A binary vertex labeling of a graph $G$ with induced edge labeling $f^{*}: E \rightarrow\{0,1\}$ defined by $f^{*}(e=u v)=f(u) f(v)$ is called a product cordial or vertex product cordial labeling if $\left|v_{f}(1)-v_{f}(0)\right| \leq 1$ and $\left|e_{f^{*}}(1)-e_{f^{*}}(0)\right| \leq 1$. A graph $G$ is cordial if it admits cordial labeling.

In 2004 Sundaram, Ponraj and Somsundaram [10] proved that unicyclic graph of odd order, triangular snakes, dragons, helms and union of two paths are product cordial. They also proved that a graph with $p$ vertices and $q$ edges 
with $p \geq 4$ is product cordial then $q<\frac{p^{2}-1}{4}+1$. In 2010 Vaidya and Kanani investigated product cordial labeling for the shadow graph of cycle $C_{n}$. The following type of problems can be considered in the area of vertex product cordial labeling.

- How vertex product cordial labeling is affected under various graph operations.

- Construct new families of vertex product cordial graphs by finding suitable labeling.

Vaidya, Dani, Kanani, Barasara and Vyas have investigated vertex product cordial labeling for cycle related graphs, friendship graph, middle graph of path and tensor graph. Vaidya and Barasara proved that friendship graph, cycle with one chord, cycle with twin chord are product cordial graphs [3]. Vaidya and Dani [12] proved that the graph obtained by joining apex vertices of two stars is product cordial and similar results for shell and wheel graphs. The path union of $k$ copies of cycle $C_{n}$ (the graph obtained by joining two copies of cycle $C_{n}$ by path $P_{k}$ ) is proved product cordial by Vaidya, Dani, Kanani $[12,15]$. The graph obtained by joining the connected components of respective graphs by a path of arbitrary length is proved product cordial by Vaidya and Vyas [19].

Definition 1.4. A vertex of degree one is called a pendant vertex.

Definition 1.5. $G^{+}=G \odot K_{1}$ is the graph obtained by joining exactly one pendant edge to every vertex of a graph $G$.

Definition 1.6. The corona product $G_{1} \odot G_{2}$ of two graphs $G_{1}$ and $G_{2}$ is defined as a graph obtained by one copy of $G_{1}$ (which has $p_{1}$ vertices) and $p_{1}$ copies of $G_{2}$ and joining $i$ th vertex of $G_{1}$ with an edge to every vertex in the $i$ th copy of $G_{2}$.

Definition 1.7. $C_{n}^{t}$ is the graph constructed from a cycle $C_{n}$ by joining two vertices whose distance in the cycle is $t$. Similarly, for the gear graph $G_{n}^{t}$ is the graph constructed from the gear graph $G_{n}$ by joining two vertices whose distance in the gear graph is $t$.

Definition 1.8. Let $G_{1}, G_{2}, \ldots, G_{n}$ be a family of disjoint stars. Let $v$ be a new vertex. The tree obtained by joining $v$ to one pendant vertex of each star is called a banana tree. The class of all such trees is denoted by $B T\left(G_{1}, G_{2}, \ldots, G_{n}\right)$.

Definition 1.9. A vertex switching $G_{v}$ of a graph $G$ is the graph obtained by taking a vertex $v$ of $G$, removing all the edges incident to $v$ and adding edges joining $v$ to every other vertex which are not adjacent to $v$ in $G$. 
In this paper, we prove that vertex product cordial labeling of path $P_{n}^{2}$, gear graph $G_{n}$. We also discuss vertex product cordial labeling of gear graph $G_{n}^{4}, P_{n} \odot K_{1}$, the banana tree $B T\left(n_{1}, n_{2}, n_{3}\right)$, corona product $C_{n} \odot K_{1}$, ladder graph $P_{n} \times P_{2}$ with one edge path to one vertex and $C_{n} \odot \bar{K}_{m}$.

\section{Main Results}

With the definition of vertex product cordial graph in the previous section in hand, we are ready to study vertex product cordial labeling for certain graphs. First we discuss vertex product cordial labeling for some path related graphs.

Theorem 2.1. $P_{n}^{2}$ is vertex product cordial graph for odd $n$.

Proof. Let $P_{n}^{2}$ be the graph with vertices $v_{1}, v_{2}, \ldots, v_{n}$. We have $\left|V\left(P_{n}^{2}\right)\right|=$ $n$ and $\left|E\left(P_{n}^{2}\right)\right|=2 n-3$. Define the labeling $f: V\left(P_{n}^{2}\right) \rightarrow\{0,1\}$ as follows:

$$
f\left(v_{i}\right)= \begin{cases}1 & \text { for } 1 \leq i \leq\left[\frac{n}{2}\right]+1 \\ 0 & \text { for }\left[\frac{n}{2}\right]+1<i \leq n\end{cases}
$$

In view of the above labeling pattern, we have

$$
v_{f}(1)=\left[\frac{n}{2}\right]+1, \quad v_{f}(0)=\left[\frac{n}{2}\right]
$$

and

$$
e_{f^{*}}(1)=n-2 \quad \text { and } \quad e_{f^{*}}(0)=n-1 \text { and the result holds. }
$$

Example 2.1. The graph $P_{5}^{2}$ and its vertex product cordial labelling is shown in Figure 1.

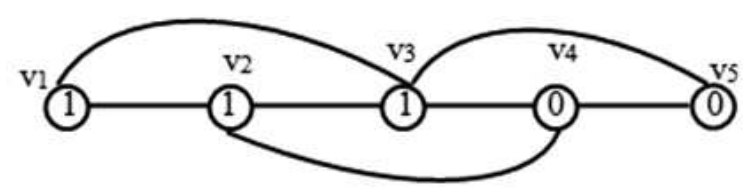

Figure 1: Vertex product cordial labeling of $P_{5}^{2}$.

Theorem 2.2. $\quad P_{n}^{2}$ is not vertex product cordial graph for even $n$. 
Proof. The graph $P_{n}^{2}$ has $n$ vertices and $2 n-3$ edges. Assign 1 to $n / 2$ vertices, so that the vertex condition form the product graph is satisfied. The vertices with label 1 cause $n-3$ edges to have label 1 and at most $n$ edges to have label 0 . Therefore $\left|e_{f^{*}}(1)-e_{f^{*}}(0)\right|=3$. So the edge condition for vertex product cordial graph is not satisfied.

Hence $P_{n}^{2}$ is not a vertex product cordial graph for even $n$.

Theorem 2.3. The path union of $k$ copies of graph $P_{n}^{2}$ admits vertex product cordial labeling.

Proof. Let $G$ be the path union of $k$ copies $G_{1}, G_{2}, \ldots, G_{k}$ of $P_{n}^{2}$. Let $\left\{v_{i 1}, v_{i 2}, \ldots, v_{i n}\right\}$ be the vertex set and $v_{i n} v_{i+1,1}$ be the edge joining $G_{i}$ and $G_{i+1} \cdot|V(G)|=n k$ and $|E(G)|=2 k(n-1)-1$. We define the labeling as follows $f: V(G) \rightarrow\{0,1\}$.

Case 1: $k$ is even, $\forall n$.

$$
\begin{array}{ll}
f\left(v_{i j}\right)=1 & \text { for } 1 \leq i \leq k / 2,1 \leq j \leq n, \\
f\left(v_{i j}\right)=0 & \text { for } \frac{k}{2}+1 \leq i \leq k \text { and } 1 \leq j \leq n .
\end{array}
$$

In view of the above labeling pattern, we have

$$
v_{f}(1)=v_{f}(0)=\frac{n k}{2}
$$

and

$$
e_{f^{*}}(1)=\left[\frac{2 k(n-1)-1}{2}\right], e_{f^{*}}(0)=\left[\frac{2 k(n-1)-1}{2}\right]+1
$$

So the vertex condition and edge conditions of vertex product cordial labeling are satisfied.

Case 2: $k$ is odd and $n$ is also odd.

$$
\begin{aligned}
& f\left(v_{i j}\right)=1 \text { for } 1 \leq i \leq\left\lceil\frac{k}{2}\right] \forall j, \\
& f\left(v_{i j}\right)=1 \text { for } i=\left[\frac{k}{2}\right]+1 \text { and } 1 \leq j \leq\left[\frac{n}{2}\right]+1, \\
& f\left(v_{i j}\right)=0 \text { for } i=\left[\frac{k}{2}\right]+1 \text { and }\left[\frac{n}{2}\right]+2 \leq j \leq n, \\
& f\left(v_{i j}\right)=0 \text { for }\left[\frac{k}{2}\right]+1 \leq i \leq k \text { and } 1 \leq j \leq n .
\end{aligned}
$$


It can be easily seen that the vertex conditions and edge conditions of product cordial labeling are satisfied either $\left|v_{f}(1)-v_{f}(0)\right| \leq 1$ and $\left|v_{f^{*}}(1)-v_{f^{*}}(0)\right| \leq$ 1.

Remark 2.1. The path union of $k$ copies of $P_{n}^{2}$ does not admits vertex product cordial labeling for odd $k$ and even $n$. Assign 1 to $\frac{n k}{2}$ vertices, so that the vertex condition form the product cordial graph is satisfied. The vertices with label 1 cause $n k-k-2$ edges to have label 1 and at most $n k-k+1$ edge to have label 0 . Therefore $\left|v_{f^{*}}(1)-v_{f^{*}}(0)\right|=3$. So the edge condition for product cordial graph is not satisfied.

Example 2.2. The product cordial labeling of path union of 2-copies of $P_{5}^{2}$ in Figure 2. It is the case related $k$ even and $n$ odd. Product cordial labeling of path union of 2 copies of $P_{5}^{2}$.

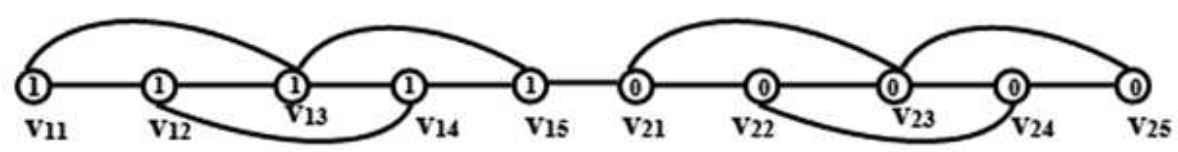

Figure 2: Vertex product cordial labeling of path union of 2 copies of $P_{5}^{2}$.

Theorem 2.4. $\quad P_{n} \odot K_{1}$ admits vertex product cordial labeling.

Proof. Let $G=P_{n} \odot K_{1}$, with $v_{1}, v_{2}, \ldots, v_{n}, u_{1}, u_{2}, \ldots, u_{n}$ vertices and $v_{1} v_{2}, v_{2} v_{3}, \ldots, v_{n-1} v_{n}, v_{1} u_{1}, v_{2} u_{2}, \ldots, v_{n} u_{n}$ edges. Consider the vertex labeling $f: V(G) \rightarrow\{0,1\}$ defined by

$$
\begin{aligned}
& f\left(v_{i}\right)=1 \quad \text { for } 1 \leq i \leq n \\
& f\left(u_{i}\right)=0 \quad \text { for } 1 \leq i \leq n
\end{aligned}
$$

In view of the above defined labeling we have $v_{f}(1)=v_{f}(0)=n$ and $e_{f^{*}}(1)=$ $n-1, e_{f *}(0)=n$.

Thus, $\left|e_{f^{*}}(1)-e_{f^{*}}(0)\right| \leq 1$ and $\left|v_{f}(0)-v_{f}(1)\right| \leq 1$. So $P_{n} \odot K_{1}$ admits vertex product cordial labeling for all $n$.

Example 2.3. Vertex product cordial labeling for $P_{4} \odot K_{1}$ is shown in Figure 3. 


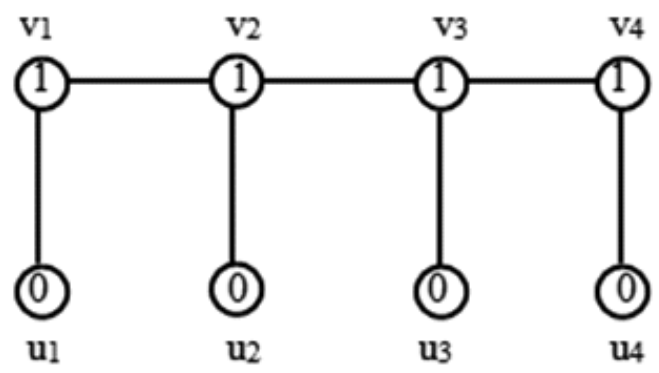

Figure 3: Vertex product cordial labeling of $P_{4} \odot K_{1}$

\section{Vertex Product Cordial Labeling of Helm Graph and Gear Related Graphs}

Definition 3.1. The helm $H_{n}$ is the graph obtained from a wheel $W_{n}$ by attaching a pendant edge to each rim vertex. It contains three types of vertices: an apex of degree $n, n$ vertices of degree 4 and $n$ pendant vertices.

Definition 3.2. The gear graph $G_{n}$ is obtained from the wheel $W_{n}$ by subdividing each of its rim edge.

Theorem 3.1. $H_{n}$ is a vertex product cordial graph.

Proof. Let $v$ be the apex, $v_{1}, v_{2}, \ldots, v_{n}$ be the vertices of degree 4 and $u_{1}, u_{2}, \ldots, u_{n}$ be the pendant vertices of $H_{n}$. Then $\left|V\left(H_{n}\right)\right|=2 n+1$ and $\left|E\left(H_{n}\right)\right|=3 n$. We define vertex labeling $f: V(G) \rightarrow\{0,1\}$ as follows:

Case 1: $n$ is even.

$f(v)=1$,

$$
f\left(v_{i}\right)= \begin{cases}1 & \text { for } 1 \leq i \leq \frac{n}{2}+1 \\ 0 & \text { for } \frac{n}{2}+2 \leq i \leq n\end{cases}
$$

and

$$
f\left(u_{i}\right)= \begin{cases}1 & \text { for } 1 \leq i \leq \frac{n}{2}-1 \\ 0 & \text { for } \frac{n}{2} \leq i \leq n\end{cases}
$$

In view of the above defined labeling pattern we have $v_{f}(1)=n+1$ and $v_{f}(0)=n$ and $e_{f^{*}}(1)=e_{f^{*}}(0)=\frac{3 n}{2}$. So $\left|v_{f}(1)-v_{f}(0)\right| \leq 1$ and $\mid e_{f^{*}}(1)-$ $v_{f^{*}}(0) \mid \leq 1$. Hence, $H_{n}$ admits vertex product cordial labeling for even $n$. 
Case 2: $n$ is odd.

$f(v)=1$,

$$
f\left(v_{i}\right)= \begin{cases}1 & \text { for } 1 \leq i \leq\left[\frac{n}{2}\right]+1 \\ 0 & \text { for }\left[\frac{n}{2}\right]+2 \leq i \leq n\end{cases}
$$

and

$$
f\left(u_{i}\right)= \begin{cases}1 & \text { for } 1 \leq i \leq\left[\frac{n}{2}\right] \\ 0 & \text { for }\left[\frac{n}{2}\right]+1 \leq i \leq n\end{cases}
$$

In view of the above labeling pattern we have $v_{f}(1)=n+1, v_{f}(0)=n$ and $e_{f *}(1)=\left[\frac{3 n}{2}\right]$ and $e_{f *}(0)=\left[\frac{3 n}{2}\right]+1$.

Thus, $\left|v_{f}(1)-v_{f}(0)\right| \leq 1$ and $\left|e_{f^{*}}(1)-v_{f^{*}}(0)\right| \leq 1$.

Example 3.1. Vertex product cordial labeling for $H_{8}$ is shown in Figure 4.

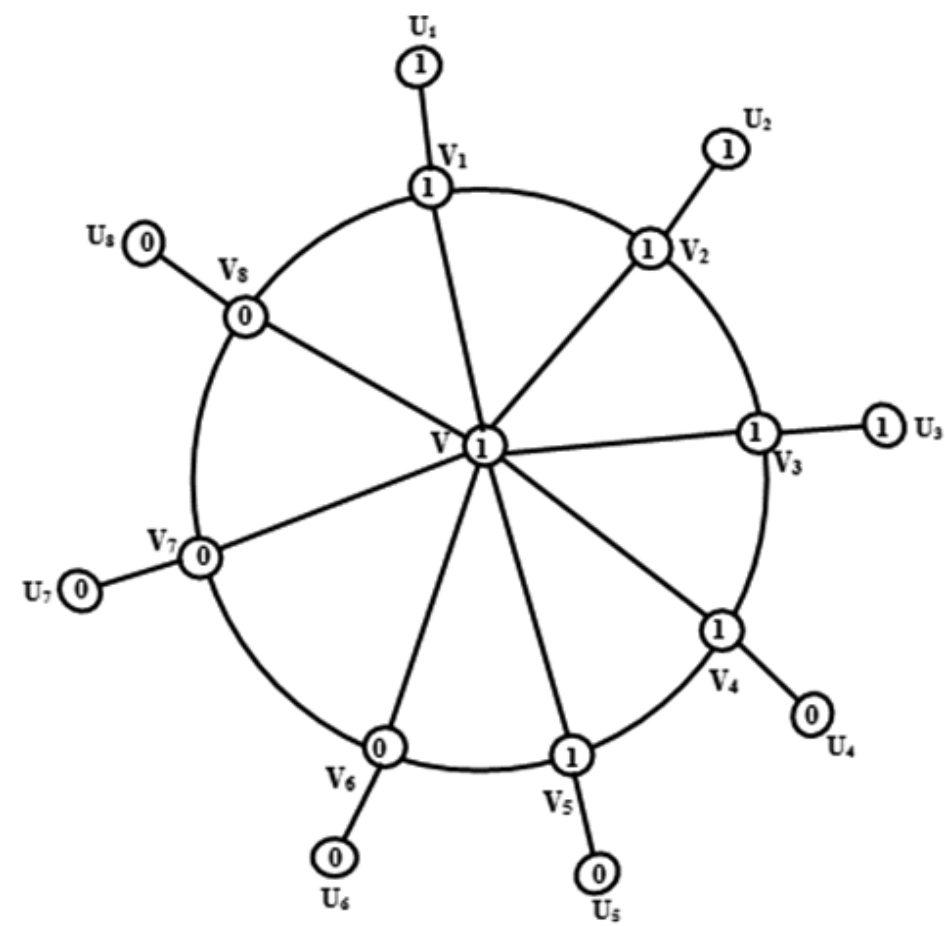

Figure 4: Vertex product cordial labeling of $H_{8}$. 
Theorem 3.2. The gear graph $G_{n}$ is vertex product cordial graph for odd $n$.

Proof. Let $u$ be the apex vertex of gear graph $G_{n}$ and $v_{1}, v_{2}, \ldots, v_{n}$ and $u_{1}, u_{2}, \ldots, u_{n}$ be the rim vertices. Consider the vertex labeling $f: V\left(G_{n}\right) \rightarrow$ $\{0,1\}$ defined by $f(u)=1$,

$$
f\left(v_{i}\right)= \begin{cases}1 & \text { for } 1 \leq i \leq\left[\frac{n}{2}\right]+1 \\ 0 & \text { for }\left[\frac{n}{2}\right]+1<i \leq n\end{cases}
$$

and

$$
f\left(u_{i}\right)= \begin{cases}1 & \text { for } 1 \leq i \leq\left[\frac{n}{2}\right] \\ 0 & \text { for }\left[\frac{n}{2}\right]+1 \leq i \leq n\end{cases}
$$

In view of the above defined labeling we have

$$
\begin{array}{ll}
v_{f}(1)=n+1, & v_{f}(0)=n \\
e_{f^{*}}(1)=\left[\frac{3 n}{2}\right], & e_{f^{*}}(0)=\left[\frac{3 n}{2}\right]+1
\end{array}
$$

Hence the gear graph $G_{n}$ is vertex product cordial graph for odd $n$.

Example 3.2. The gear graph $G_{7}$ with its vertex cordial labelling is shown in Figure 5.

Remark 3.1. In the above theorem we can write $v_{2}, v_{4}, \ldots$ in place of $u_{1}, u_{2}, \ldots$ so on.

Theorem 3.3. The gear graph $G_{n}^{4}$ with a chord admits vertex product cordial labelling for even $n>4$.

Proof. Let $u$ be the apex vertex of the gear graph $G_{n}$ and $v_{1}, v_{2}, \ldots, v_{2 n}$ be the rim vertices of $G_{n}$. Let $v_{1} v_{5}$ be the chord in $G_{n}$. Then $\left|V\left(G_{n}\right)\right|=2 n+1$ and $|E(G)|=3 n+1$, we define $f: V\left(G_{n}\right) \rightarrow\{0,1\}$ as follows

$$
\begin{aligned}
& f(u)=1, \\
& f\left(v_{i}\right)=1, \quad \text { for } 1 \leq i \leq n-1, \quad f\left(v_{n}\right)=0 \\
& f\left(v_{i}\right)=1, \quad \text { for } i=n+1 \\
& f\left(v_{i}\right)=0, \quad \text { for } n+2 \leq i \leq 2 n
\end{aligned}
$$




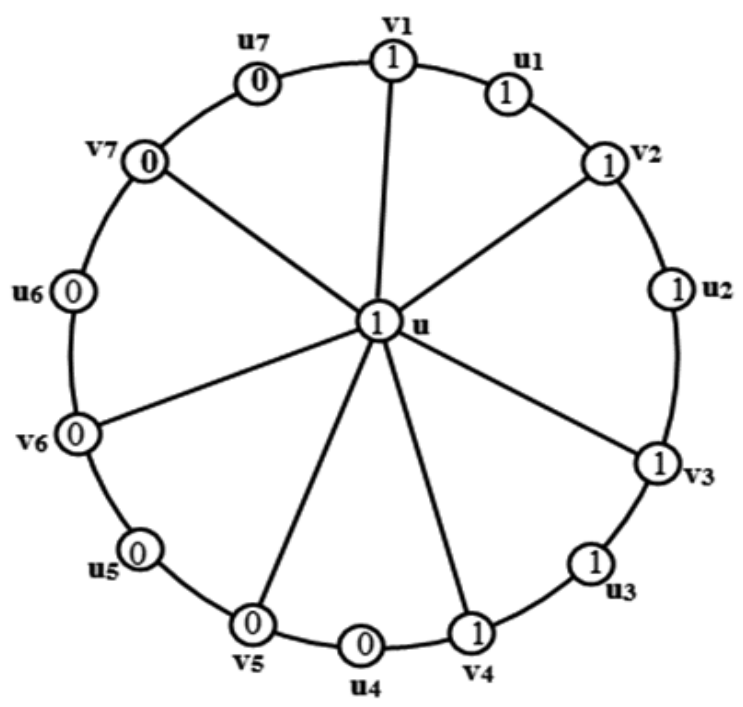

Figure 5: Vertex product cordial labeling of $G_{7}$.

In view of the above defined labeling pattern we have $v_{f}(1)=n+1, v_{f}(0)=$ $n$ and $e_{f *}(1)=\frac{3 n}{2}, e_{f^{*}}(0)=\frac{3 n}{2}+1$. Hence, then graph $G_{n}^{4}$ admits vertex product cordial labeling.

Example 3.3. For better understanding of the above defined labeling pattern the vertex product cordial labeling of $G_{8}^{4}$ is shown in Figure 6 . In this labeling $n$ is even.

\section{Switching of a Vertex and Vertex Product Cordial Labeling}

Theorem 4.1. Switching of a vertex in cycle $C_{n}$ admits vertex product cordial labeling.

Proof. Let $v_{1}, v_{2}, \ldots, v_{n}$ be the successive vertices of $C_{n}$ and $G_{v_{1}}$ denotes the graph obtained by switching of a vertex $v_{1}$ of $G=C_{n}$. Then $\left|V\left(G_{v_{1}}\right)\right|=n$ and $\left|E\left(G_{v_{1}}\right)\right|=2 n-5$. We define the vertex labeling $f: V\left(G_{v_{1}}\right) \rightarrow\{0,1\}$ as follows: 


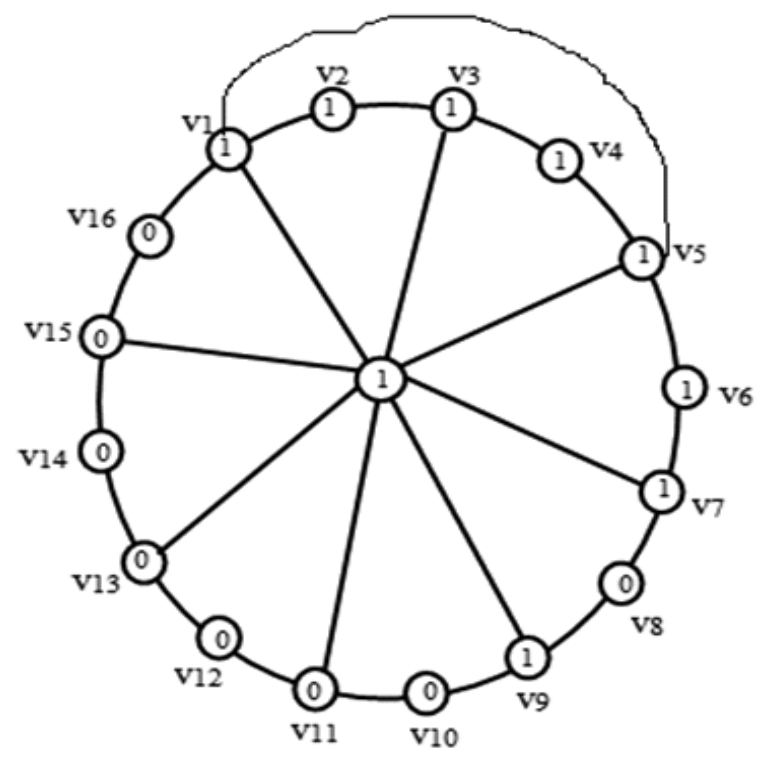

Figure 6: Vertex product cordial labeling of $G_{8}^{4}$.

Case 1: when $n$ is even.

$f\left(v_{1}\right)=1, f\left(v_{2}\right)=0$,

$$
f\left(v_{i}\right)= \begin{cases}1 & \text { for } 3 \leq i \leq \frac{n}{2}+1 \\ 0 & \text { for } \frac{n}{2}+2 \leq i \leq n .\end{cases}
$$

In view of the above defined labeling pattern we have $v_{f}(1)=v_{f}(0)=\frac{n}{2}$ and $e_{f *}(1)=n-3, e_{f *}(0)=n-2$. Thus $\left|v_{f}(1)-v_{f}(0)\right| \leq 1$ and $\left|e_{f *}(1)-e_{f *}(0)\right| \leq 1$

Case 2: when $n$ is odd. $f\left(v_{1}\right)=1, f\left(v_{2}\right)=0$,

$$
f\left(v_{i}\right)= \begin{cases}1 & \text { for } 3 \leq i \leq\left[\frac{n}{2}\right]+2 \\ 0 & \text { otherwise }\end{cases}
$$

In view of the above defined labeling pattern we have $v_{f}(1)=\left[\frac{n}{2}\right]+1, v_{f}(0)=$ $\left[\frac{n}{2}\right]$ and $e_{f^{*}}(1)=\left[\frac{2 n-5}{2}\right]+1, e_{f *}(0)=\left[\frac{2 n-5}{2}\right]$. Thus the required condition of vertex product cordial labeling is satisfied.

Example 4.1. Switching of a vertex in cycle $C_{9}$ namely $G_{9}$ with its vertex product cordial graph is shown in Figure 7. 


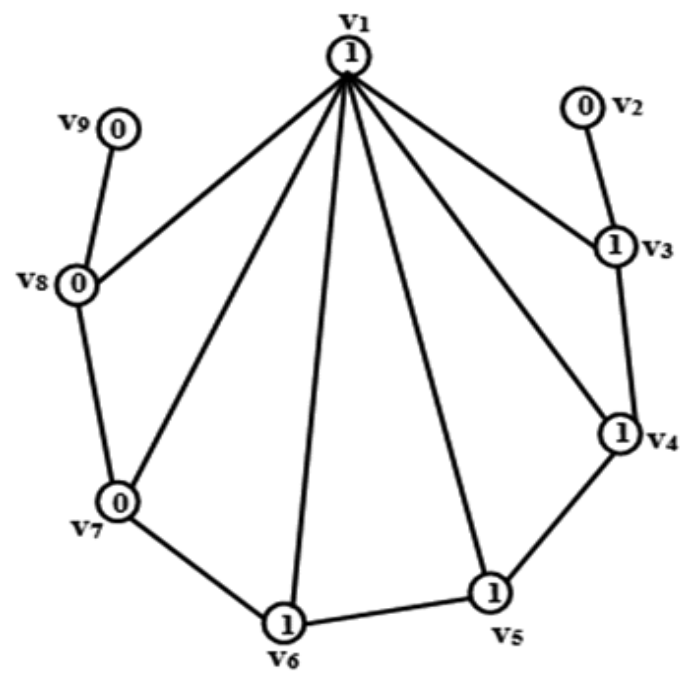

Figure 7: $G_{9}$ with its vertex product cordial labeling

\section{Vertex Product Cordial Labeling for some Product Related Graphs}

In this section, we exhibit vertex product cordial labeling for some product related graphs like $C_{n} \odot K_{1}$, ladder graph $P_{n} \times P_{2}$ with a 1-edge path attached to its one vertex and for $C_{n} \odot \bar{K}_{m}$.

Theorem 5.1. The corona product $C_{n} \odot K_{1}$ admits vertex product cordial labeling for all $n$.

Proof. Let $G=C_{n} \odot K_{1}$ and $\left\{v_{1}, v_{2}, \ldots, v_{n}\right\}$ be the set of cycle vertices and $\left\{u_{1}, u_{2}, \ldots, u_{n}\right\}$ be the set of pendant vertices for the graph $C_{n} \odot K_{1}$ where $u_{i}$ is adjacent to $v_{i}, v_{i} v_{i+1}$ if $i \in\{1,2,3, \ldots, n-1\}$. For Corona product $C_{n} \odot K_{1}$, $\left|V\left(C_{n} \odot K_{1}\right)\right|=2 n$ and $\left|E\left(C_{n} \odot K_{1}\right)\right|=2 n$ we define $f: V\left(C_{n} \odot K_{1}\right) \rightarrow\{0,1\}$ as follows:

$$
\begin{aligned}
& f\left(u_{i}\right)=1 \quad \text { for } 1 \leq i \leq n \\
& f\left(v_{i}\right)=1 \quad \text { for } 1 \leq i \leq n
\end{aligned}
$$

In view of the above defined labeling pattern we have $v_{f}(1)=v_{f}(0)=n$ and $e_{f^{*}}(1)=e_{f^{*}}(0)=n$. So $\left|v_{f}(1)-v_{f}(0)\right| \leq 1$ and $\left|e_{f^{*}}(1)=e_{f^{*}}(0)\right| \leq 1$. Hence the corona product $C_{n} \odot K_{1}$ admits vertex product cordial labeling. 
Example 5.1. The Corona product $C_{6} \odot K_{1}$ with its vertex product cordial labeling is shown in Figure 8.

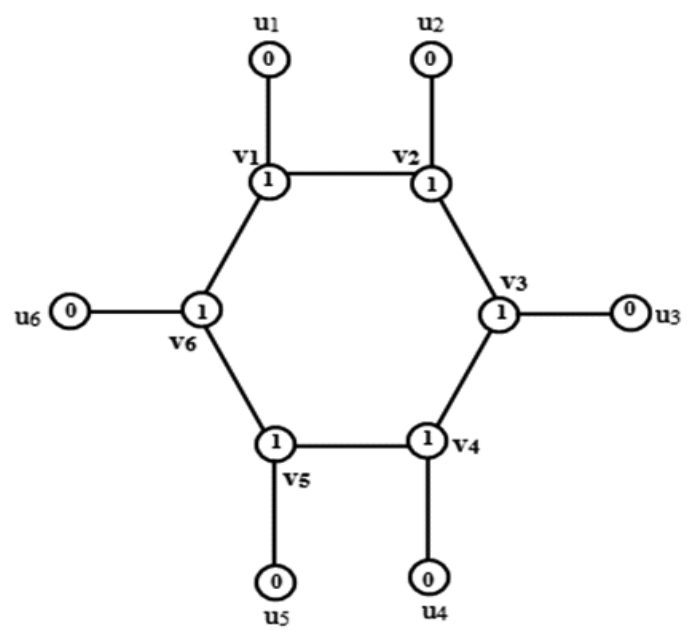

Figure 8: $C_{6} \odot K_{1}$ with its vertex product cordial labeling.

Theorem 5.2. The graph $G$ obtained by attaching a 1-edge path to one-vertex of a ladder graph $P_{n} \times P_{2}$ is vertex product cordial.

Proof. Let $G$ be the graph obtained by attaching 1-edge path to one-vertex of a ladder graph $P_{n} \times P_{2}$. Let $V(G)=\left\{v, v_{1}, v_{2}, \ldots v_{n}, u_{1}, u_{2}, \ldots, u_{n}\right\}$ and the edge set $E(G)=\left\{v_{i} v_{i+1}: 1 \leq i \leq n-1\right\} \cup\left\{u_{i} u_{i+1}: 1 \leq i \leq n-1\right\} \cup\left\{u_{i} v_{i}\right.$ : $1 \leq i \leq n\} \cup\left\{v_{n} v\right\}$. Clearly $|V(G)|=2 n+1$ and $|E(G)|=3 n-1$. We define the vertex labeling $f: V(G) \rightarrow\{0,1\}$ as follows:

Case 1. $n$ is odd. Then

$$
\begin{aligned}
& f\left(v_{i}\right)=1 \quad \text { for } 1 \leq i \leq\left[\frac{n}{2}\right]+1, \\
& f\left(v_{i}\right)=0 \quad \text { for }\left[\frac{n}{2}\right]+2 \leq i \leq n \\
& f\left(u_{i}\right)=1 \quad \text { for } 1 \leq i \leq\left[\frac{n}{2}\right]+1, \\
& f\left(u_{i}\right)=0 \quad \text { for }\left[\frac{n}{2}\right]+2 \leq i \leq n, \\
& \text { and } \\
& f(v)=0 .
\end{aligned}
$$


In view of the above defined labeling $v_{f}(1)=\left[\frac{2 n+1}{2}\right]+1, v_{f}(0)=\left[\frac{2 n+1}{2}\right]$ and $e_{f^{*}}(0)=e_{f^{*}}(1)=\frac{3 n-1}{2}$.

Case 2. $n$ is even. Then

$$
\begin{aligned}
& f\left(v_{i}\right)=1 \quad \text { for } 1 \leq i \leq \frac{n}{2}+1, \\
& f\left(v_{i}\right)=0 \quad \text { for } \frac{n}{2}+2 \leq i \leq n, \\
& f\left(u_{i}\right)=1 \quad \text { for } 1 \leq i \leq \frac{n}{2}, \\
& f\left(u_{i}\right)=0 \quad \text { for } \frac{n}{2}+1 \leq i \leq n, \\
& \text { and } \\
& f(v)=0 .
\end{aligned}
$$

In view of the above defined labeling $v_{f}(1)=n+1, v_{f}(0)=n$ and $e_{f^{*}}(0)=$ $\left[\frac{3 n-1}{2}\right]+1, e_{f *}(1)=\left[\frac{3 n-1}{2}\right]$.

One can observe that in each case the labeling defined above satisfies the conditions of vertex product cordial labeling and the graph under consideration is vertex product cordial.

Illustration. For better understanding of the above defined labeling pattern the vertex product cordial labeling of ladder graph $P_{5} \times P_{2}$ with one chord is shown in Figure 9. In this labeling $n$ is odd.

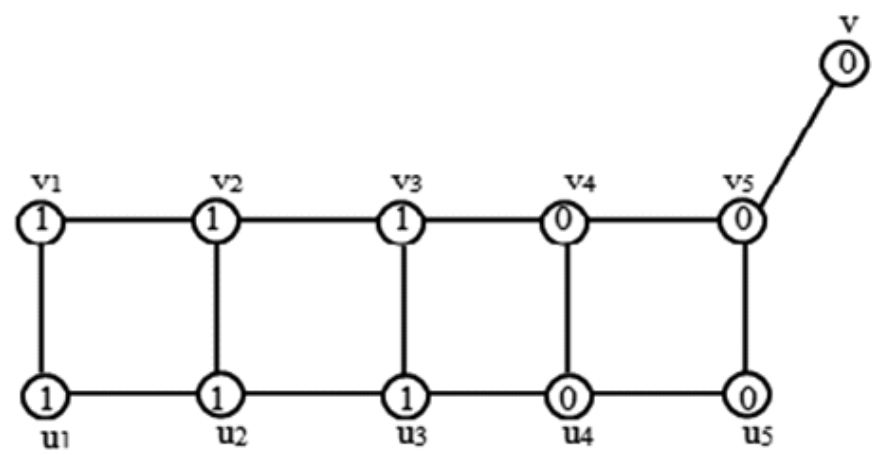

Figure 9: Vertex product cordial labeling of $P_{5} \times P_{2}$ with one chord

Theorem 5.3. $\quad C_{n} \odot \bar{K}_{m}$ admits vertex product cordial labeling for odd $n$ and even $m$.

Proof. Let the vertex set $V=\left\{u_{i}: 1 \leq i \leq n\right\} \cup\left\{u_{i j}: 1 \leq i \leq n, 1 \leq j \leq m\right\}$ and the edge set $E=\left\{u_{i} u_{i+1}, u_{n} u_{1}: 1 \leq i \leq n-1\right\} \cup\left\{u_{i} u_{i j}: 1 \leq i \leq n, 1 \leq\right.$ 
$j \leq m\}$. Here $|V|=m n+n,|E|=m n+n$. We define $f: V(G) \rightarrow\{0,1\}$

$$
\begin{aligned}
& f\left(u_{i}\right)=1 \quad \text { for } 1 \leq i \leq\left[\frac{n}{2}\right]+1 \\
& f\left(u_{i}\right)=0 \quad \text { for }\left[\frac{n}{2}\right]+2 \leq i \leq n \\
& f\left(u_{i j}\right)=1 \quad \text { for } i=1,2, \ldots,\left[\frac{n}{2}\right], 1 \leq j \leq m ; \\
& f\left(u_{i j}\right)=1 \quad \text { for } i=\left[\frac{n}{2}\right]+1,1 \leq j \leq m / 2 ; \\
& f\left(u_{i j}\right)=0 \quad \text { for } i=\left[\frac{n}{2}\right]+1, \frac{m}{2}+1 \leq j \leq m ; \\
& f\left(u_{i j}\right)=0 \quad \text { for } i=\left[\frac{n}{2}\right]+2, \ldots, n ; 1 \leq j \leq m .
\end{aligned}
$$

In view of the above defined labeling pattern we have $v_{f}(0)=\left[\frac{m n+n}{2}\right]$, $v_{f}(1)=\left[\frac{m n+n}{2}\right]+1$ and $e_{f^{*}}(1)=\left[\frac{m n+n}{2}\right], e_{f^{*}}(0)=\left[\frac{m n+n}{2}\right]+1$. Hence, the graph $C_{n} \odot \bar{K}_{m}$ is vertex product cordial graph.

Example 5.2. Graph $C_{6} \odot K_{1}$ with its vertex product cordial labeling is shown in Figure 10.

Theorem 5.4. Let $G=B T\left(n_{1}, n_{2}, n_{3}\right)$. If $n_{1}=n_{2}=n_{3}=n$, then $G$ admits vertex product cordial labeling.

Proof. Let the vertex set

$$
V(G)=\left\{s, v, v_{1}, v_{2}, \ldots, v_{n}, u, u_{1}, u_{2}, \ldots, u_{n}, w, w_{1}, w_{2}, \ldots, w_{n}\right\}
$$

and the edge set $E(G)=\left\{s v_{n}, s u_{n}, s w_{n}\right\} \cup\left\{v v_{i}: 1 \leq i \leq n\right\} \cup\left\{u u_{i}: 1 \leq i \leq\right.$ $n\} \cup\left\{w w_{i}: 1 \leq i \leq n\right\}$. Clearly $|V(G)|=3 n+4$ and $|E(G)|=3 n+3$. Define $f: V(G) \rightarrow\{0,1\}$ as follows:

$$
\begin{aligned}
& f(s)=f(v)=f(u)=1, f(w)=0, \\
& f\left(v_{n}\right)=f(w n)=f\left(u_{n}\right)=1 \\
& f\left(v_{i}\right)=1 \quad \text { for } 1 \leq i \leq n-1 \\
& f\left(u_{i}\right)=0 \quad \text { for } 1 \leq i \leq n-1 \\
& f\left(w_{i}\right)=0 \quad \text { for } 1 \leq i \leq n-1 .
\end{aligned}
$$

Case 1: When $n$ is even.

In view of the above defined labeling

$$
v_{f}(1)=\frac{3 n+4}{2}=v_{f}(0) \text { and }
$$




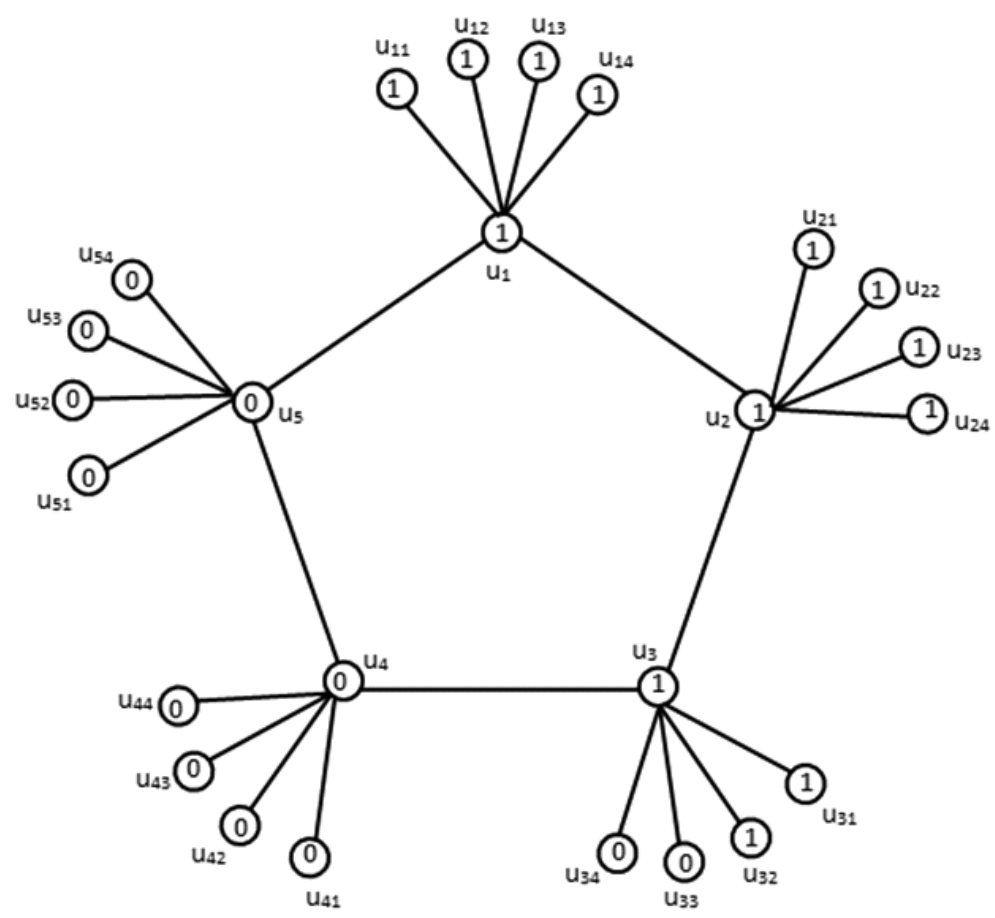

Figure 10: $C_{6} \odot K_{1}$ with its vertex product cordial labeling

$$
e_{f}(1)=\left[\frac{3 n+3}{2}\right], e_{f}(0)=\left[\frac{3 n+3}{2}\right]+1
$$

Hence the result holds for even $n$.

Case 2: When $n$ is odd.

In case 2 we have

$$
\begin{aligned}
& v_{f}(1)=\left[\frac{3 n+4}{2}\right]+1, \quad v_{f}(0)=\left[\frac{3 n+4}{2}\right] \text { and } \\
& e_{f^{*}}(1)=e_{f^{*}}(0)=\frac{3 n+3}{2} .
\end{aligned}
$$

Hence the Banana tree $B T\left(n_{1}, n_{2}, n_{3}\right), n_{1}=n_{2}=n_{3}=n$ is a vertex product cordial graph.

Example 5.3. The Banana tree $B T(6,6,6)$ with its vertex product cordial graph is shown in Figure 11. 


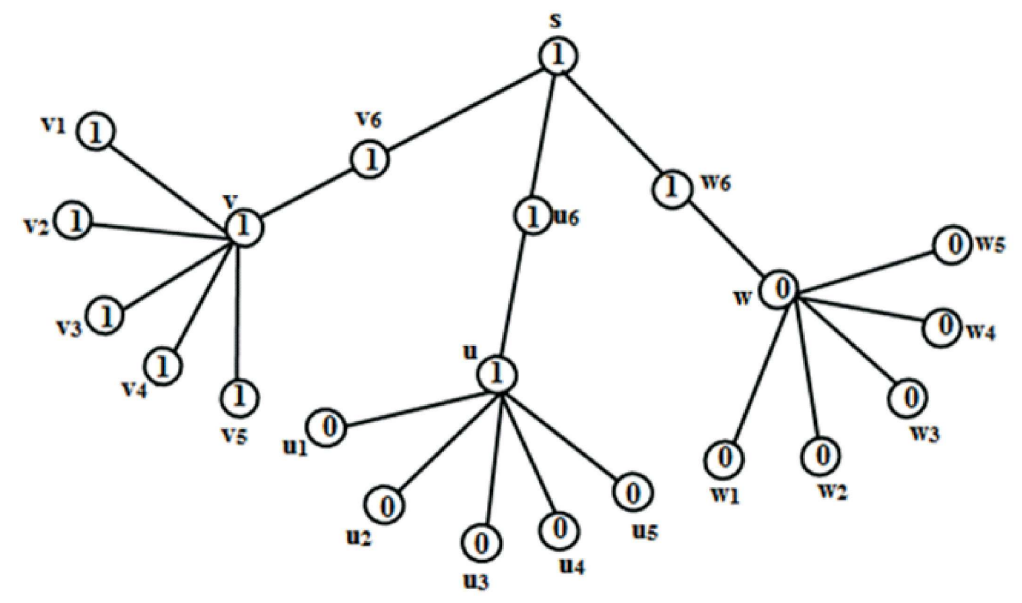

Figure 11: Vertex product cordial labeling of $B T(6,6,6)$.

\section{References}

[1] I. Cahit, Cordial graphs: A weaker version of graceful and harmonious graphs, Ars Combinatoria, 23 (1987), 201-207.

[2] S. M. Lee and A. Liu, A construction of $k$-graceful graphs from complete bipartite graphs, SEA BULL Math., 12 (1988), 23-30.

[3] J. A. Gallian, A dynamic survey of graph labeling, The Electronics Journal of Combinatorics, 19 (2012), 1-260.

[4] F. Harary, Graph Theory, Addision-Wesley, Reading, MA (1969).

[5] A. Rosa, On certain valuations of the vertices of a graph, Theory of graphs, International Symposium, Rome (1966), Gordon and Breach, New York and Dunod Paris, 1967, 349355.

[6] Y. S. Ho, S. M. Lee and S.C. Shee, Cordial labeling of unicyclic graphs and generalized Petersen graphs, Congr. Numer., 68 (1989), 109-122.

[7] M. A. Seoud and A.E.I. Abdel Maqsoud, On cordial and belanced labeling of graphs, J. Egyptian math. Soc., 7 (1999), 127-135.

[8] M. A. Seoud, A.T. Diab and E.A. Elsahawi, On stronglyharmonious, relatively prime, odd graceful and cordial graph, Proc. Math. Phys. Soc. Egypt, 73 (1998), 33-55.

[9] M. A. Seoud and A.E.I. Abdel Maqsoud, On 3-equitable and magic labeling, preprint.

[10] M. Sundaram, R. Ponraj and S. Somasundaram, Product cordial labeling of graphs, Bull. Pure and Applied Science (Mathematics and Statistics), 23 (2004), 155-163.

[11] M. Sundaram, R. Ponraj and S. Somasundaram, Prime cordial labeling of graphs, Journal of the Indian Academy of Mathematics, 27 (2) (2005), 373-390.

[12] S. K. Vaidya and N. A. Dani, Some new product cordial graphs, Journal of App. Comp. Sci. Math., 8 (4) (2010), 62-65. 
[13] S. K. Vaidya and C. M. Barasara, Product cordial labeling for some new graphs, Journal of Mathematics Research, 3 (2) (2011), 206-211.

[14] S. K. Vaidya and C. M. Barasara, Some product cordial graphs, Elixir Discrete Mathematics, 41 (2011), 5948-5952.

[15] S. K. Vaidya and K. K. Kanani, Some cycle related product cordial graphs, Int. J. of Algorsithms, Comp. and Math., 3 (1) (2010), 109-116.

[16] S. K. Vaidya and N. H. Shah, Some new families of prime cordial graphs, Journal of Mathematics Research, 3 (4) (2011), 21-30.

[17] S. K. Vaidya and P. L. Vihol, Prime cordial labeling of some graphs, Modern Applied Science, 4 (8) (2010), 119-126.

[18] S. K. Vaidya and P. L. Vihol, Prime cordial labeling for some cycle related graphs, International Journal of Open Problems in Computer Science and Mathematics, 3 (5) (2010), 223-232.

[19] S. K. Vaidya and N. B. Vyas, Product cordial labeling in the context of tensor product of graphs, Journal of Mathematics Research, 3 (3) (2011), 83-88. 